\title{
LA PROPIEDAD Y LA TENSIÓN ENTRE CAMBIO Y ESTABILIDAD: REFLEXIONES PARA UNA CONSTITUCIÓN SUSTENTABLE
}

\author{
PROPERTY AND THE TENSION BETWEEN STABILITY AND \\ CHANGE: REFLECTIONS FOR A SUSTAINABLE CONSTITUTION
}

MATÍAS GUILOFF TITIUN***

\section{RESUMEN}

Este trabajo enfatiza el papel que juega el derecho de propiedad privada en la articulación de la tensión entre estabilidad y cambio que es inherente a todo sistema jurídico. Para ello, se centra en la interpretación de este Derecho que se efectúa en el proceso legislativo al momento de debatir un proyecto de ley que puede generar repercusiones patrimoniales. Específicamente, devela dos concepciones o interpretaciones del derecho de propiedad privada que se han usado para proteger posiciones o situaciones patrimoniales en la práctica legislativa durante la vigencia de la Constitución del 80 (la concepción extendida y absoluta) e ilustra el rol que juega la posibilidad de control preventivo por parte del tribunal constitucional en el peso que estas concepciones tengan en el debate legislativo. Finalmente, considerando la incidencia que esta posibilidad puede tener en la articulación de la tensión entre estabilidad y cambio, enfatiza la necesidad de no contemplar el control

\footnotetext{
* Abogado. Licenciado en Derecho, Universidad Diego Portales, LL.M. Columbia University (2007), SJ.D. University of Arizona (2014). Profesor del Departamento de Derecho Público, Universidad Diego Portales, Santiago, Chile. Correo electrónico matias.guiloff@udp.cl. ORCID: https://orcid. org/0000-0002-8622-1538.

** Agradezco los comentarios y sugerencias de Javier Couso, Maite Gambardella, George Lambeth, Domingo Lovera, Viviana Ponce de León, Constanza Salgado, Pablo Soto y Pablo Torres.

Artículo recibido el 10 de marzo de 2021 y aceptado para su publicación el 25 de junio de 2021.
} 
preventivo en el nuevo texto constitucional y recalca el importante papel que le incumbe al legislador al configurar los títulos que permiten el ejercicio de actividades económicas, como también en el eventual establecimiento de mecanismos que faciliten el tránsito entre regímenes normativos que se genera como consecuencia del establecimiento de una reforma.

Palabras clave: Estabilidad; Cambio; Concepción absoluta del derecho de propiedad privada; Concepción extendida del derecho de propiedad privada; control preventivo; cultura jurídica.

\section{ABSTRACT}

This paper emphasizes the role that the right to private property plays in articulating the tension between stability and change that is inherent to any legal system. It does so by focusing on the interpretations of this right that are offered whenever Congress debates a bill that might have important economic repercussions. The paper therefore unveils two conceptions or interpretations of this right that have been used to shield economic entitlements from legislative intervention during the rule of the Chilean 1980 Constitution (the extended and the absolute conception) and illustrates the role that the sole possibility of having the constitutional court exerting is preventative review powers plays on the weight that such conceptions are given on in the legislative debate. Lastly, and considering the impact that such possibility might have in the articulation of the tension between stability and change, it argues for not including it in the new Constitution and underscores the important role of the legislature in shaping economic entitlements, as well as in establishing mechanisms that facilitate those legal transitions that the approval of any amendment triggers.

Keywords: Stability; Change; Absolute conception of the right to private property; Extended conception of the right to private property; preventative review powers; legal culture. 


\section{INTRODUCCIÓN}

El proceso legislativo es la manera que hemos ideado para establecer cambios de manera pacífica en una comunidad política. ${ }^{1}$ Los arreglos institucionales que han sido de suma utilidad en un momento dado para cumplir objetivos económicos y sociales fácilmente pueden tornarse disfuncionales para la satisfacción de las necesidades existentes en el presente y en el futuro próximo. Con todo, esos arreglos no solo quedan materializados en los textos legales en que se contienen, sino también en una serie de situaciones, respaldadas por una diversidad de instrumentos legales (tales como, entre otros, contratos, obligaciones y títulos).

Dicho en términos breves y sencillos, al amparo de un determinado arreglo institucional se construyen realidades materiales y legales, de forma tal que todo cambio que se introduzca a este afecta, en mayor o menor medida, a aquellas realidades. Esto ilustra que dentro de un sistema legal, la necesidad de cambios convive con la de estabilidad y se genera una tensión entre una y otra. ${ }^{2}$ Por lo anterior, la manera en que se articulen los arreglos que permiten el establecimiento de cambios o protegen la estabilidad resulta crucial para la sustentabilidad de una determinada comunidad política.

Quizás el medio más paradigmático para resguardar la estabilidad en el ámbito patrimonial es el derecho de propiedad privada. En principio, es razonable pensar que mientras menos protegido se encuentre este derecho, más fácil será para la legislación introducir cambios que tengan repercusiones patrimoniales. A la inversa, en tanto más robusta sea la protección de este derecho, más difícil será ir actualizando los marcos legales a las necesidades económicas y sociales existentes. En suma: al incidir en la inevitable tensión entre la necesidad de cambio y la de estabilidad, la regulación del derecho de propiedad privada también resulta crucial para que el pacto social que rige a una comunidad política sea sostenible en el tiempo.

Uno de los grandes desafíos que el proceso constituyente en curso deberá enfrentar es el de establecer una regulación adecuada del derecho

\footnotetext{
${ }^{1}$ NoRTH, Douglas, Institutions, institutional change and economic performance, Cambridge University Press, New York, 1991, pp. 89-90.

2 Véase, en general: NonEt, Philippe; SelznICK, Phillip, Law \& Society in Transition. Towards Responsive Law., Transaction Publishers, New Brunswick, 2008, 4a ed.; Luhmann, Niklas, "Operational Closure and Structural Coupling: the Differentiation of the Legal System", Cardozo Law Review, 1992, Vol. $13, \mathrm{n}^{\circ} 5, \mathrm{p} .1427$.
} 
de propiedad privada, así como la de otros mecanismos que tienen un impacto crucial en el rol que este juega al momento de articular la tensión anteriormente mencionada, como es el caso, según se recalcará, de la facultad de controlar preventivamente los proyectos de ley que se le otorga al Tribunal Constitucional. Para saber cómo regular estos aspectos en una nueva Constitución Política puede ser de utilidad revisar las interpretaciones o concepciones relativas a la protección del derecho de propiedad privada que se han planteado en el Congreso al momento de discutir la introducción de reformas legales de alcances patrimoniales durante la vigencia de la Constitución de 1980 y analizar críticamente sus implicancias. Ese es precisamente el objetivo del presente artículo.

Como quedará en evidencia, por más que la Constitución de 1980 no ampara con el derecho de propiedad privada todas las posiciones o situaciones de relevancia patrimonial concebibles y no obstante que consagra una amplia potestad legislativa para configurar y limitar este derecho, ${ }^{3}$ al momento de debatir reformas en el Congreso el legislador ha estimado que cuenta con un margen acotado sino inexistente para efectuar las intervenciones sobre situaciones o posiciones económicas requeridas para introducir ajustes al marco regulatorio de una actividad económica, sea que estas se encuentren efectivamente resguardadas por esta garantía o no. Las concepciones sobre el alcance e inviolabilidad de la propiedad privada (en adelante, la concepción extendida y absoluta, respectivamente), esgrimidas bajo la amenaza de una eventual impugnación de la modificación debatida ante el tribunal constitucional, y con prescindencia de que ésta finalmente se haya materializado, han tenido un peso argumentativo suficiente para bloquear las reformas propuestas o morigerar significativamente la incidencia de estas sobre el status quo, y de paso la aptitud de ellas para cumplir los objetivos que procuraban satisfacer. No es razonable pensar que estas concepciones van a desaparece por el solo hecho de tener una nueva constitución. Si lo es, en cambio, estimar que su fuerza no será tanta si se alteran los arreglos institucionales que las han dotado de una particular fuerza, como lo es precisamente la posibilidad del control preventivo por parte del tribunal

\footnotetext{
${ }^{3}$ Es importante recordar que de acuerdo al inciso 2 del artículo $19 \mathrm{~N}^{\circ} 24$, "(e)sta comprende cuanto exijan los intereses generales de la Nación, la seguridad nacional, la utilidad y la salubridad públicas y la conservación del patrimonio ambiental". El énfasis es mío.
} 
constitucional. $^{4}$

El trabajo revela además la necesidad de obrar con cautela al momento de configurar los títulos que permiten a agentes privados realizar actividades económicas (tales como, por ejemplo, autorizaciones, permisos y concesiones). Ello porque es en ese instante donde el legislador configura el marco de expectativas, y eventualmente derechos, cuya vulneración posteriormente podrá ser alegada por estos agentes cuando surja la necesidad de modificar dichos títulos. ${ }^{5} \mathrm{Si}$ en la configuración inicial se les otorgan unos atributos que permitan la creación de situaciones de una significativa relevancia patrimonial, luego será muy difícil introducir modificaciones tanto al marco legal como a la realidad material creada a su amparo.

Para desarrollar este argumento el artículo utilizará la siguiente estructura. En la primera parte se describirá la concepción extendida del derecho de propiedad privada, se analizarán sus implicancias y se ilustrará su influjo sobre la práctica constitucional haciendo referencia a un debate legislativo donde ha tenido un particular impacto (el de las varias reformas a la ley de pesca que han procurado regular el acceso a los recursos hidrobiológicos por parte de los agentes económicos del sector pesquero industrial). Luego, en la segunda, se hace exactamente lo mismo con la concepción absoluta del derecho de propiedad privada, usando para ilustrarla el debate legislativo concerniente a la introducción de la caducidad por no uso en el Código de Aguas. Finalmente, en las conclusiones se analizará qué cabe esperar sobre la protección de este derecho bajo una nueva Constitución, enfatizando que la manera en que esta articule la tensión entre cambio y estabilidad dependerá, por una parte, de si se mantiene o no el citado control y, por la otra, de la práctica legislativa al momento de realizar la configuración inicial de los títulos que permiten el desarrollo de actividades económicas. En esa sección, asimismo, se hace hincapié en la necesidad de reparar más en el rol que juega el legislador en la configuración y delimitación de este derecho, así como en la distribución y eventual mitigación de los costos generados por las transiciones que originan los cambios legales.

\footnotetext{
${ }^{4}$ GuIloff, Matías, "El estatuto constitucional de la propiedad: una mirada ex ante", en: ChíA, E.; Quezada, F. (Eds.), Propuestas para una nueva Constitución (Originada en democracia), Instituto Igualdad, Santiago, 2015, p. 117.

${ }^{5}$ Sobre el rol de las expectativas como fundamento de las alegaciones de vulneración del derecho de propiedad privada, ver Michelman, Frank, "Property, Utility and Fairness: Comments on the Ethical Foundations of Just Compensation Law", Harvard Law Review, 1967, n 80, pp. 1239-1245.
} 
Antes de partir, es necesario explicitar que este artículo no pretende realizar una descripción y análisis acabado de todos los aspectos relativos a la regulación constitucional de la propiedad privada. Su énfasis es más bien ahondar en las concepciones relativas a este derecho que inciden en la articulación de la tensión entre estabilidad y cambio. Por esta razón, no se analizan otros que no se relacionan necesariamente y de manera tan directa con ella, tales como la regulación detallada de la expropiación, la configuración específica del estatuto propietario sobre los recursos minerales y la posibilidad de imponer limitaciones a este derecho para proteger el derecho a vivir en un medio ambiente libre de contaminación, prevista en el inciso 2 del artículo $19 \mathrm{~N}^{\circ} 8$. Asimismo, y dado su foco en el rol del derecho de propiedad privada en la articulación de la tensión entre estabilidad y cambio, este trabajo solo se centra en el rol de este derecho en las discusiones legislativas y no aborda lo relativo a eventuales afectaciones a este por parte de la administración, ${ }^{6}$ como tampoco hace un acabado análisis acabado sobre la jurisprudencia relativa a este derecho. ${ }^{7}$

\section{LA CONCEPCIÓN EXTENDIDA DEL DERECHO DE PROPIEDAD PRIVADA}

Como toda institución legal, el derecho de propiedad privada tiene un ámbito de aplicación, pero los contornos precisos de este no se encuentran totalmente determinados. Efectivamente, de acuerdo a la Constitución de 1980, este opera sobre toda clase de bienes, corporales e incorporales. Como se podrá intuir, los problemas de determinación se presentan respecto de los segundos. Para una mejor comprensión de estas dificultades cabe explicar muy someramente en qué consisten estos bienes.

De acuerdo al Código Civil chileno, "[1] os bienes consisten en cosas corporales e incorporales" (art. 565), "[1] as cosas incorporales son derechos

\footnotetext{
${ }^{6}$ Sobre este punto en particular, ver RAJEvIC, Enrique, "Limitaciones, reserva legal y contenido esencial de la propiedad privada", Revista Chilena de Derecho, 1996, Vol. 23, ํ1, pp. 30-40, y Guiloff, Matías, "Elija cuál derecho de propiedad privada se protege. La precisión de las normas legales que establecen limitaciones a la propiedad privada, a propósito de los fallos Molinera del Norte y curtido Bas", Anuario de Derecho Público UDP, 2016, n 1, pp. 159-165.

${ }^{7}$ Ver Matute, Claudio, Regulaciones Expropiatorias. Aplicabilidad al caso chileno, Legal Publishing, Santiago, 2014, pp. 114-174.
} 
reales o personales" (art. 576) y "[s]obre las cosas incorporales hay también una especie de propiedad. Así el usufructuario tiene la propiedad de su derecho de usufructo (art. 583)". ${ }^{8}$ En términos sencillos, los bienes incorporales son derechos que el legislador ha decidido amparar configurándolos como bienes respecto de los cuales es posible ejercer una titularidad,

En ciertas ocasiones, la decisión legislativa de otorgarle esta configuración a un derecho puede ser explícita. Esto se evidencia, por ejemplo, en la Ley $N^{\circ} 19.657$ sobre Concesiones de Energía Geotérmica, cuyo artículo 5 inciso 2 establece: "[e]l titular de una concesión de energía geotérmica tiene sobre la concesión un derecho de propiedad, protegido por la garantía contemplada en el artículo 19 de la Constitución política y por las demás normas jurídicas que sean aplicables al mismo derecho". ${ }^{9}$ En otras, sin embargo, puede no serla tanto, por lo que el status de cosa incorporal solo se podrá determinar luego de realizar un ejercicio interpretativo. Tómese por caso lo que sucede con las licencias transables de pesca, que de acuerdo a los artículos 26 y 30 de la Ley $\mathrm{N}^{\mathrm{o}} 20.657$, tienen una duración de 20 años y son "divisibles, transferibles, transmisibles y susceptibles de todo negocio jurídico".

El contraste anteriormente descrito permite advertir desde ya que la dificultad de determinar qué es un bien incorporal amparado por el derecho de propiedad privada no solo es consecuencia de la falta de corporalidad material de estos, sino que de las diversas configuraciones legales que presentan las posiciones y situaciones patrimoniales que pueden formar parte o no del elenco de estos bienes, cuestión que en la mayoría de los casos solo se zanjará luego de un ejercicio interpretativo. A su vez, como lo que se encuentra en juego es el tipo de protección que se le brinda a una situación o posición económica (por ejemplo, a la titularidad sobre una autorización de pesca), este ejercicio interpretativo, lejos de ser un evento episódico, se termina realizando en la generalidad de las situaciones en que se discute la modificación del marco regulatorio de una actividad económica. Y esto se explica por las consecuencias patrimoniales que se siguen del tipo de protección que se decida otorgar. En efecto, si se concluye que la situación

\footnotetext{
${ }^{8}$ Guiloff, Matías; Salgado, Constanza, "Derecho de propiedad", en: Contreras, P.; Salgado, C. (Eds.), Curso de Derechos Fundamentales, Tirant Lo Blanch, Santiago, 2020, p. 500.

${ }^{9}$ Ejemplo tomado de PonCE DE León, Viviana, La problemática invocación a la confianza legítima como límite a la potestad legislativa, Estudios Constitucionales, 2014, año 12, n 1, p. 446.
} 
o posición jurídica objeto de análisis se encuentra amparada por el derecho de propiedad privada, por considerarse que el legislador ha configurado una titularidad sobre el título que habilita su ejercicio, el legislador solo puede modificarla cumpliendo con las exigencias del artículo $19 \mathrm{~N}^{\mathrm{o}} 24$ inciso 2 y para privar a su titular de ella deberá utilizar la expropiación.

Desde la perspectiva histórica, la utilización estratégica del derecho de propiedad en amparo de posiciones o situaciones de significancia patrimonial, sea que se encuentren efectivamente amparadas por esta garantía o no, no es para nada algo novedoso. Ya desde la segunda mitad del siglo XIX en Estados Unidos, como da cuenta HorwiTz, una parte de la literatura constitucional argumentaba que una regulación que tenía un efecto negativo sobre el margen de ganancia de una actividad económica afectaba el derecho de propiedad privada. ${ }^{10} \mathrm{Y}$, para no ir tan lejos, en nuestro país también se ha ocupado frecuentemente este derecho para reclamar ante los tribunales de justicia, a través del recurso de protección, la afectación de toda clase de situaciones patrimoniales. ${ }^{11}$ Tanto es así que la doctrina mostró su preocupación por lo receptiva que fue la jurisprudencia a este tipo de argumentaciones, y mientras algunos hablaron de "inflación de los derechos", ${ }^{12}$ otros lo hicieron de "propietarización de los derechos". ${ }^{13}$

Sostener que una determinada situación se encuentra amparada por el derecho de propiedad por el solo hecho de que ella tiene un valor económico o contenido patrimonial, y con prescindencia de la manera en que haya sido configurada por el legislador, evidencia una concepción particularmente amplia -por no decir voluntarista- del derecho de propiedad privada. En lo que sigue la denominaremos la concepción extendida del derecho de propiedad. Cabe señalar que esta es extendida porque abarca cualquier situación o posición jurídica que tenga un valor económico. Como se indicará algunos párrafos más adelante, esta concepción se ha utilizado con particular éxito en la práctica legislativa durante la vigencia de la Constitución de 1980. Antes

\footnotetext{
${ }^{10}$ Horwitz, Morton, The transformation of American law, 1870-1960: The Crisis of Legal Orthodoxy, Oxford University Press, Oxford, 1994, p. 151.

${ }^{11}$ Vergara, Alejandro, "La propietarización de los derechos", Revista de Derecho P. Universidad Católica de Valparaíso, 1992, Vol. 14, pp. 289-290. Cabe mencionar que esta argumentación y jurisprudencia incluso se extendió a los incumplimientos contractuales, véase, en general, JANA, Andrés; MARín, Juan Carlos, Recurso de protección y contratos, Editorial Jurídica de Chile, Santiago, 1996.
}

${ }^{12}$ Guzmán Brito, Alejandro, Las cosas incorporales en la Doctrina y en el Derecho positivo, Editorial Jurídica de Chile, Santiago, 1995, pp. 99-103.

${ }^{13}$ Vergara, cit. (n. 11), p. 290. 
de eso, es pertinente dar cuenta de las consecuencias legales y políticas que se siguen de ella.

El problema que genera esta aproximación es que, al hacer depender de una circunstancia fáctica, como lo es el hecho de que tenga o no un determinado valor de mercado, el tipo de protección legal que se le otorga a una posición jurídica, desliga la configuración del derecho de propiedad de la voluntad legislativa. En términos sencillos, bastaría con que una situación o posición jurídica tenga un valor económico para concluir que se encuentra amparada por el derecho de propiedad privada. ${ }^{14}$ Esto resulta complejo en la medida que el valor de un bien en un momento dado depende de una serie de factores contingentes y más o menos aleatorios, tales como, solo por decir algunos, los de orden político, social, cultural y geográfico. ${ }^{15}$ Entonces, si se afirma que algo por el solo hecho de tener un valor de mercado se encuentra amparado por el derecho de propiedad privada, la articulación de la tensión entre estabilidad y cambio se entrega a estos factores contingentes y aleatorios, en vez de a las definiciones y orientaciones que establezca la legislación.

Además, y entrando de lleno a la relación de esta concepción con la administración de esta tensión, ella puede incidir negativamente sobre la sustentabilidad del orden político-económico. Ello se debe a que, si entendemos que toda posición o situación valiosa se encuentra resguardada por el derecho de propiedad privada, entonces cada vez que se haga necesario revisar el régimen legal al que se encuentra sujeta serán aplicables las garantías y exigencias que la Constitución prevé para las intervenciones gubernamentales sobre el derecho de propiedad privada (reserva legal y contenido esencial, tratándose de su regulación, y expropiación, en lo referente a su privación). Cómo es evidente, el cumplimiento de ellas a lo menos dilatará la introducción de estos ajustes y en algunos casos incluso los bloqueará, lo que terminará sucediendo si en el respectivo debate se impone la concepción absoluta de la propiedad, lo que ha sucedido durante la vigencia de la Constitución de 1980, según se describirá en la próxima sección.

${ }^{14}$ Para un análisis crítico de definiciones laxas del derecho de propiedad proveniente del análisis económico del Derecho, ver Cole, Daniel; Grossman, Peter, "The meaning of property rights: Law versus economics", Land Economics, 2002, Vol. 78, N 3, pp. 322-325.

${ }^{15}$ Ver FrIED, Barbara, The progressive assault on laissez faire. Robert Hale and the first law and economics movement, Harvard University Press, Cambridge, 1998, pp. 82-83, 127-12 y 281-282. 
Por último, antes de revisar un ejemplo que ilustra la incidencia de la concepción extendida en la práctica legislativa, es importante explicitar y recalcar la importancia del vínculo entre la configuración del derecho de propiedad y la protección que se le otorgue a las expectativas de estabilidad del marco normativo. Al momento de establecer la regulación de una determinada actividad económica, el legislador tiene distintas alternativas dependiendo de los objetivos que procure satisfacer. Así, por ejemplo, si busca crear un mercado secundario para los instrumentos o títulos que permitan la realización de una actividad relacionada con la explotación de un recurso escaso, como podría ser la pesca o las telecomunicaciones, es razonable que el legislador los configure otorgándole atributos que faciliten su comerciabilidad y los dote de una estabilidad que otorgue incentivos suficientes para efectuar inversiones en dicho mercado. Adicionalmente, si quiere dar certeza absoluta, puede establecer explícitamente que el titular tiene un derecho de propiedad sobre estos títulos, como lo ha hecho para las concesiones geotérmicas. ${ }^{16} \mathrm{O}$, inversamente, atendiendo al hecho que se trata de un recurso escaso, sobre el cual es razonable que el Estado se deje un margen para ir introduciendo los ajustes que demuestre necesario el tiempo, puede establecer explícitamente, como según veremos a continuación se ha hecho en Chile, que la asignación de estos títulos no podrá ser interpretado como la concesión de derecho de propiedad alguno.

Más que las diversas opciones a disposición del legislador para establecer la regulación detallada de una actividad económica específica, el punto central a enfatizar aquí es la relevancia de la configuración que este efectúe para cuan persuasivas puedan ser las expectativas de estabilidad que los agentes económicos posteriormente puedan invocar. Como se indica en

\footnotetext{
${ }^{16}$ Estas concesiones constituyen un caso de propiedad regulatoria, es decir, derechos de propiedad creados instrumentalmente por el legislador al regular una determinada actividad económica, por considerar que su establecimiento asegurará de mejor manera el cumplimiento de sus objetivos. Sobre la propiedad regulatoria, ver en general: SERKIN, Christopher, "Penn Central take two", Notre Dame Law Review, 2017, Vol. 92, № 2; y Wyman, Katrina, "Second Generation Property Rights Issues", Natural Resources Journal, 2019, Vol. 59, No 1. Con todo, como enfatiza Wyman, dada la incidencia que pueden llegar a tener los intereses económicos organizados en la política, no es para nada descartable que, en los hechos, el establecimiento de esquemas basados en la propiedad regulatoria resulte ineficiente, dado que no necesariamente existirá correspondencia entre lo que resulte eficiente para la sociedad y aquello que finalmente determine el proceso político, ver Wyman, Katrina, "Problematic private property: The case of New York Taxicab Medallions", Yale Journal on Regulation, 2013, Vol. 30, p. 125. El interesantísimo tema sobre la diferencia entre esta propiedad regulatoria y lo que la literatura nacional ha denominado los "derechos reales administrativos" excede los objetivos de este trabajo.
} 
la literatura estadounidense sobre propiedad y transiciones legales, a falta de elementos adicionales, el argumento que las reglas del juego no pueden cambiar porque alguien había realizado inversiones bajo la expectativa que estas iban a permanecer inmutables, es circular. ${ }^{17}$ ¿Cuáles son entonces esos elementos adicionales? Precisamente, los analizados en el párrafo anterior: los que haya establecido el legislador al configurar el título que permite la realización de la actividad económica (sus atributos y estabilidad). Si además de la existencia de un valor de mercado, el marco regulatorio aplicable al título otorga indicios que quiso otorgar estabilidad mediante el establecimiento de elementos como los anteriormente descritos y esta se ve afectada por un cambio súbito y abrupto, entonces el caso en favor de proteger las expectativas de estabilidad puede ser más persuasivo, ${ }^{18}$ en la medida que se demuestre una afectación de carácter singular al momento de aplicarse la nueva normativa a una situación o posición económica concreta.

Un caso que resulta muy llamativo para ilustrar la incidencia de la concepción absoluta sobre la posibilidad de introducir ajustes a los marcos regulatorios es el de las reformas a la legislación pesquera, en el que, como veremos a continuación, la concepción absoluta ha sido útil para impedir el establecimiento de ajustes. ${ }^{19} \mathrm{Al}$ respecto, cabe señalar que la necesidad de establecer modificaciones de implicancias económicas significativas al marco regulatorio de este sector se empieza a evidenciar a mediados de la década de los 80, cuando el nivel de explotación de varios recursos pesqueros alcanzó niveles preocupantes. Para lidiar con esta situación se propuso limitar el acceso a estos mediante una reforma a la regulación de esta actividad económica. Este esfuerzo se materializó, primero, en la dictación de la ley $\mathrm{N}^{\mathrm{o}} 18.892$ y luego en la de las leyes $\mathrm{N}^{\mathrm{o}} 19.079$ y 19.080 . Estas últimas establecieron diversos regímenes de acceso en función

\footnotetext{
${ }^{17}$ Ackerman, Bruce, Private Property and the Constitution, Yale University Press, New Haven, 1977, p. 105; y DaGAN, Hanoch, "Restitution and slavery: on incomplete commodification, intergenerational justice, and legal transitions", Boston University Law Review, 2004, n 84, pp. 1168-1169.

${ }^{18}$ En defensa de la postura que la propiedad privada protege expectativas patrimoniales que puedan verse afectadas por cambios súbitos y abruptos, ver MonTt, Santiago, "Expropiaciones directas y derregulatorias y reforma regulatoria pesquera", Informe en Derecho, ante Tribunal de Defensa de la Libre Competencia, Causa Rol NC 379-10, 2010, p. 42. Para una postura similar en el Derecho comparado, ver Doremus, Holly, "Takings and Transitions", Journal of Land Use and Environmental Law, 2003, Vol. 19, n 1, p. 13.

${ }_{19}$ Esta descripción se basa en Guiloff, Matías, "Ley de Pesca: Explicando un regalo regulatorio", Anuario de Derecho Público UDP, 2013, n 1, pp. 282-285.
} 
del estado de desarrollo de las pesquerías, a saber: (a) régimen de acceso general, (b) régimen de plena explotación, (c) régimen de pesquería en recuperación y (d) régimen de pesquería incipiente. Adicionalmente, estas leyes otorgaron a la autoridad pesquera la competencia de fijar anualmente cuotas globales de captura para cada especie, aplicables para todos lo regímenes, salvo el general de acceso. Por último, y conforme a lo establecido en un artículo transitorio de la Ley $\mathrm{N}^{\circ} 19.080$, las principales pesquerías chilenas quedaron sujetas al régimen de plena explotación, el que, de acuerdo a la definición legal pertinente, es aplicable para aquellas especies hidrobiológicas que han llegado a tal nivel de explotación, que con la captura de las unidades autorizadas no existe superávit en los excedentes productivos de la respectiva pesquería.

El propósito de este régimen es precisamente controlar el esfuerzo pesquero - la capacidad de pesca de los barcos autorizados para realizar esta actividad económica- respecto de aquellos recursos hidrobiológicos cuyo nivel de abundancia ha llegado a la situación anteriormente descrita. Para lograr este propósito, una vez que se declara a una pesquería en plena explotación, la autoridad del rubro tiene la facultad de suspender el otorgamiento de nuevas autorizaciones de pesca para capturar la especie en cuestión. La consecuencia más relevante para nuestro análisis que deriva de esta declaración es que, en conformidad con las leyes aludidas, las autorizaciones de pesca que se encontraban vigentes y que ahora, tras haberse efectuado dicha declaración, permiten capturar pesquerías declaradas en plena explotación, tienen un carácter indefinido en tanto se mantenga ese régimen de acceso.

Sin embargo, a pesar de estos cambios regulatorios, el diagnóstico hacia fines de la década de los 90 era que seguían existiendo niveles excesivos de esfuerzo pesquero y que se requerían nuevos instrumentos legales. Este análisis generó la necesidad de introducir modificaciones adicionales a la legislación del sector para lidiar con este problema, lo que se hizo mediante la dictación de la Ley $\mathrm{N}^{\circ}$ 19.713. El referido cuerpo legal estableció un mecanismo denominado "límite máximo de captura por armador", que se traduce en la asignación de cuotas individuales de pesca. Esta medida de administración pesquera supone (a) fraccionar la cuota global de captura entre el sector industrial y el artesanal para, luego, (b) determinar con sujeción a ciertos parámetros cómo se asigna a armadores industriales específicos -que cuenten con autorizaciones de pesca vigentes- una alícuota de esa fracción. 
Los citados parámetros son distintos para las diversas pesquerías. Así, tratándose de las más relevantes -el jurel, la sardina y la merluza de cola-, en aquellas zonas geográficas en donde aún es posible capturarlos, estos son las capturas efectuadas por cada armador industrial en los tres años anteriores a la entrada en vigencia de la ley en cuestión y la capacidad de bodega corregida de los buques autorizados para efectuarlas. Por su parte, para el resto de las especies hidrobiológicas se consideran únicamente las capturas efectuadas en los dos años anteriores a la entrada en vigencia de esta ley. Algo importante a notar desde ya es que, al tomar en consideración capturas históricas, se trata de un sistema de asignación diseñado para impedir que los actores que hasta la fecha de dictación de esta ley no habían ingresado al mercado, puedan beneficiarse de la asignación de estas cuotas (porque nunca estuvieron en condiciones de realizar estas capturas), lo que por contrapartida reconoce y privilegia los intereses de los agentes que ya venían ejerciendo actividades pesqueras.

Si bien originalmente la Ley $\mathrm{N}^{\mathrm{o}} 19.713$ iba a tener una vigencia de solo dos años, dada la dificultad de lograr consensos en la materia, su aplicación se prorrogó por otros diez con la aprobación de la Ley $\mathrm{N}^{\mathrm{o}}$ 19.849. Cabe enfatizar que la primera de estas leyes $-\mathrm{y}$ la segunda, por cuanto prorrogó la vigencia de la anterior- fueron enfáticas en declarar que esta asignación de cuotas, efectuada en conformidad al límite máximo de captura por armador, no implicaba el otorgamiento de derecho alguno para las futuras modificaciones que se introdujeran en la materia. En efecto, el artículo 14 de la Ley $\mathrm{N}^{\circ} 19.713$ indicó a este respecto: "El establecimiento del límite máximo de captura por armador a que se refiere este título no constituirá derecho alguno en asignaciones de cualquier tipo que se efectúen en el futuro".

Esta es entonces la herencia con que se encuentra el legislador en el 2012, al expirar la vigencia de la Ley N $N^{0} 19.849$ y hacerse ineludible, en consecuencia, debatir sobre una nueva modificación a la Ley de Pesca. Dada la complejidad de la materia y la cantidad de limitaciones sustantivas y temporales aplicables a las reformas antes descritas, a continuación se realiza una breve recapitulación de estos cambios. En primer término, las leyes $\mathrm{N}^{\mathrm{o}} 19.079$ y 19.080 introdujeron el régimen de plena explotación y determinaron su aplicación para las principales pesquerías chilenas, lo que produjo la suspensión del otorgamiento de nuevas autorizaciones para capturar estas especies. Los actores que contaban con autorizaciones 
vigentes al efectuarse esta declaración pudieron seguir realizando actividades extractivas de manera indefinida pero sujeta a una calificación: en tanto la pesquería se siguiera administrando bajo el régimen de plena explotación. Luego, en virtud de las leyes $\mathrm{N}^{\mathrm{o}} 19.713$ y 19.849, las autorizaciones de pesca que incidían en las principales pesquerías del país se transformaron en cuotas individuales para aquellos armadores industriales que se vieron favorecidos por los criterios de asignación escogidos por el legislador para la determinación del límite máximo de captura por armador -aquellos cuyas inversiones les permitieron tener un número más alto de capturas y buques con una mayor capacidad de bodega. Por último, cabe recalcar que, en conformidad a lo señalado por estas modificaciones legales, las cuotas temporales en cuestión no debían ser interpretadas como constitutivas de derecho alguno para efectos de las asignaciones que se realizaran en el futuro.

Ante esta realidad, al empezar a diseñar la propuesta de modificación normativa que habría de debatirse para el sector pesquero, el gobierno de aquel entonces consideró la alternativa de utilizar el mecanismo de las licitaciones para efectos de asignar las cuotas. Desde la perspectiva legal, era bastante evidente que no existían mayores obstáculos para el establecimiento de esta alternativa, dado que la Ley $N^{\circ} 19.713$ había establecido explícitamente que quienes resultaran beneficiados con el otorgamiento de cuotas establecido por ella no podrían alegar derecho alguno para otras asignaciones que se realizaran en el futuro. ${ }^{20}$ Con todo, para aquellos que se habían beneficiado de la adjudicación de estas durante los 12 años en que rigió la Ley $\mathrm{N}^{0} 19.713$, esta opción implicaba la posibilidad cierta que nuevos agentes pudieran

\footnotetext{
${ }^{20}$ Esta disposición se encuentra en perfecta sintonía con la historia legislativa, en la cual el Senador Foxley enfatizó la importancia "que la ley en proyecto no se entienda como una consagración del statu quo en lo referente a cuotas de pesca", ver Biblioteca del Congreso Nacional (Eds.), Historia de la Ley 19.713, establece como medida de administración el límite máximo de captura por armador a las Principales Pesquerías Industriales Nacionales y la regularización del Registro Pesquero Artesanal, BCN, Santiago, 2001, disponible en línea: https://www.ben.cl/historiadelaley/nc/historia-de-laley/6065/ (Fecha de visita: 12 de abril de 2021), específicamente Legislatura 343 del Senado, Sesión 21, de 9 de enero de 2001, Discusión general, p. 291. Asimismo, respecto del mecanismo de asignación de cuotas que se estableció, llamado límite máximo de captura por armador, el Senador Horvath indicó que "no es transferible, se puede modificar, no establece derechos nuevos, ni dominio sobre el mismo", ver Informe de la Comisión de Medio Ambiente y Bienes Nacionales recaído en el proyecto de ley, en segundo trámite constitucional, que establece como medida de administración el límite máximo de captura por armador a las principales pesquerías industriales nacionales y la regularización del registro pesquero artesanal, p. 261. Para estas y otras referencias sobre la historia legislativa, ver MonTt, cit. (n. 18), p. 29-35.
} 
competir con ellos en el procedimiento licitatorio y eventualmente hacerse de estas cuotas. Dicho de otro modo, desde la perspectiva económica, esta alternativa implicaba para ellos la posibilidad de pérdida de una renta y de las inversiones que realizaron en su momento para poder ejercer la actividad de la que ella derivaba.

Dada esa repercusión patrimonial, los armadores que se verían eventualmente afectados por el establecimiento de las licitaciones argumentaron que la introducción de estas en la legislación pesquera suponía una afectación a su derecho de propiedad privada. Para que esa afirmación fuera correcta tendría que cumplirse a lo menos con una condición: que las licitaciones afectaran una situación o posición económica amparada con el derecho de propiedad privada. Y, como era de esperarse, ese fue el argumento legal preciso que elaboraron los armadores en cuestión, señalando específicamente que el establecimiento de licitaciones afectaba el derecho de propiedad que estos detentarían sobre sus autorizaciones de pesca.

Para justificar que las autorizaciones en cuestión se encontraban amparadas por este derecho, los abogados y académicos que defendieron esta postura enfatizaron lo determinante que resultaba para arribar a esa conclusión la utilidad económica que estas le entregan a sus beneficiarios, así como la naturaleza, también económica, de los atributos con los que el legislador las ha dotado al configurarlas. Así, afirmaron que el carácter de bien incorporal de estas era evidente si se consideraba que ellas permitían a sus titulares ejercer una actividad económica que para la generalidad de los agentes estaba prohibida, lo que le otorgaba una gran utilidad económica a estas autorizaciones. ${ }^{21}$ Adicionalmente, y en lo relativo a los atributos de estos títulos, realzaron la relevancia que tendría su transmisibilidad, así como su escasez y transferibilidad bajo el régimen de plena explotación, para concluir que correspondían a bienes incorporales. ${ }^{22}$ Algunos incluso llegaron a criticar la visión de los derechos de propiedad en que se fundamentaba la propuesta de licitar las cuotas, en la medida en que esta supone que estos derechos se configuran por actos del Estado, en vez de por las actuaciones

${ }^{21}$ CORREA, Jorge, "Límites constitucionales a eventuales modificaciones al régimen legal de pesca", 2010, Informe en Derecho, ante Tribunal de Defensa de la Libre Competencia, Causa Rol NC 37910, p. 36.

${ }^{22}$ Correa, cit. (n. 21); Feliú, Olga, "Informe en Derecho en representación de Asipes, Asociación de Industriales Pesqueros de la VIII región", Informe en Derecho, ante Tribunal de Defensa de la Libre Competencia, Causa Rol NC 379-10, 2010, p. 18. 
de las personas que llevan a generar vínculos con los objetos. ${ }^{23}$

Más que zanjar si las autorizaciones en cuestión se encuentran o no amparadas por este derecho, el punto relevante aquí es ilustrar el rol que juega en esta discusión la concepción extendida del derecho de propiedad privada. Como evidencian los párrafos anteriores, esta no hace otra cosa que disociar de la determinación positiva del ordenamiento jurídico el tipo de protección que se le otorga a una posición o situación económica (para este caso, su amparo a través del derecho de propiedad privada). Efectivamente, la defensa del status quo en materia de asignaciones de cuotas de pesca en este caso contradice de manera flagrante la voluntad del legislador, realizada en ejercicio de su potestad de configuración del régimen de una actividad económica y materializada en el tenor literal de la Ley $\mathrm{N}^{\circ} 19.713$, relativa a no establecer una asignación definitiva de cuotas para el sector industrial, ni menos una titularidad sobre estas. De esta manera, como se puede apreciar, la concepción extendida resulta funcional para proteger expectativas de estabilidad cuya formulación no obedece a base legal alguna. Por ello, es sumamente útil para intentar amparar la gran diversidad de posiciones o situaciones económicas que no se encuentran protegidas por el derecho de propiedad privada. ${ }^{24}$

En resumidas cuentas, la utilidad de la concepción extendida del derecho de propiedad privada reside en ampliar el ámbito de aplicación de este derecho o, dicho de otro modo, en proteger mediante este una serie de situaciones o posiciones económicas que no se encuentran respaldadas por titularidad alguna. Con todo, aun si estas recibieran este tipo de amparo, de ello no se sigue que estas sean intangibles para el legislador. Como se sabe, en relación a la propiedad, la Constitución le atribuye a este la potestad de "establecer [...] las limitaciones y obligaciones que deriven de su función social”. La cual comprende -no está de más enfatizarlo- "cuanto exijan los intereses generales de la Nación, la seguridad nacional, la utilidad y la salubridad públicas y la conservación del patrimonio ambiental”.

\footnotetext{
${ }^{23}$ V. Concha, Germán, "Ley de Pesca y derechos de propiedad", opinión, Diario La Tercera, 12 de Julio de 2011.

${ }^{24}$ Recientemente, una argumentación basada en la concepción extendida fue invocada ante el Tribunal Constitucional por una empresa pesquera para exceptuarse de la aplicación de un ajuste introducido por el legislador mediante la llamada "Ley de la Jibia", la que finalmente fue desechada. V. Tribunal Constitucional, 12 de noviembre de 2020, Rol 8614-20.
} 


\section{LA CONCEPCIÓN ABSOLUTA}

Como evidencian las disposiciones constitucionales relativas al derecho de propiedad privada, el legislador detenta una amplia potestad para imponer limitaciones y obligaciones sobre las posiciones o situaciones que este derecho ampara. Precisamente, esa potestad es el foco de la concepción absoluta del derecho de propiedad privada. Ella hace como si la Constitución no la hubiese establecido, para argumentar que, bajo el marco constitucional vigente el legislador no cuenta con atribuciones para incidir sobre posiciones amparadas mediante el derecho de propiedad privada -por eso es absoluta, porque no admite modulación alguna-. Dicho de otro modo, sustituye la propiedad limitada por su función social establecida en la actual constitución, y que se consagró por primera vez en la reforma constitucional de $1967,{ }^{25}$ por una inviolable, como la establecida en la Constitución de 1833 y también en la de 1925 (aunque de manera mucho más matizada). ${ }^{26}$

Lo anterior permite advertir nítidamente que la función social de la propiedad, que se encuentra explicita y detalladamente consagrada en el texto constitucional, es la gran afectada por la concepción absoluta. Efectivamente, dicha concepción le niega a la función social el poder que la Constitución le reconoce: ajustar los marcos regulatorios que inciden en derechos de propiedad a lo que la realidad vaya demostrando como necesario, para resguardar ciertos intereses que se consagran a través de conceptos jurídicos más o menos indeterminados como, entre otros, la utilidad pública, salubridad pública y la conservación del patrimonio ambiental. Como consecuencia de ello, si para el bienestar de la comunidad se requiere hacer una reforma que afecte negativamente una posición protegida por el derecho de propiedad privada, y ya que en los hechos no hay función social, la única vía que le queda al legislador es expropiar al afectado, pagándole la compensación que corresponda. Esto, aun cuando, la medida no niegue su titularidad sobre la posición involucrada ni suponga un traslado de esta

\footnotetext{
${ }^{25}$ Para un análisis sobre esta reforma, ver en general: Evans, Enrique, Estatuto constitucional del derecho de propiedad en Chile, Editorial Jurídica de Chile, Santiago, 1967.

${ }^{26}$ Esta última Constitución indicó que el ejercicio de este derecho estaba sometido a las "limitaciones o reglas que exijan el mantenimiento y el progreso del orden social", y dotaba al legislador de la potestad de imponer obligaciones o servidumbres de utilidad pública en favor de los intereses generales del estado, la salud de los ciudadanos y la salubridad pública. Ver Constitución Política de 1925 (Chile), artículo 10 $\mathrm{N}^{\mathrm{o}} 10$
} 
última al patrimonio del Estado. Como se podrá advertir, y en consonancia con lo que se indicó en la introducción, un entendimiento así del derecho de propiedad privada, en el que esta no admite ningún tipo de intervención sin compensación y en donde la función social queda relegada a una mera declaración romántica, hace insostenible el gobierno de una comunidad política. ${ }^{27}$

Con todo, es importante recalcar que, por más tosca que sea, esta concepción es una manera de defenderse de algo que efectivamente puede ser un problema: los impactos patrimoniales que puede tener una modificación legal. Siguiendo la tendencia mundial, el ordenamiento jurídico constitucional chileno no contempla resguardo alguno frente al riesgo que implica la potencial magnitud de estos efectos. ${ }^{28}$ Ante esta situación, y dadas las repercusiones patrimoniales que hay en juego, no resulta para nada sorprendente que quienes vean su situación económica amenazada por una reforma que se está debatiendo, le atribuyan al derecho de propiedad el poder de consagrar una suerte de inmunidad patrimonial perpetua frente a la regulación gubernamental. Sin embargo, esa pretensión choca de frente con los términos claros y explícitos que la Constitución Política utiliza para regular detalladamente el ejercicio de la potestad configuradora del derecho de propiedad privada por parte del legislador a los que ya se hizo alusión. ${ }^{29}$

Ciertamente, una vez aprobadas y en su aplicación a un determinado contexto fáctico que al momento de establecerlas no se pudo prever, una limitación u obligación a la propiedad puede implicar una carga pública injusta o desproporcionada. De ser así, existen mecanismos para aliviar la situación del afectado. En Francia, por lo pronto, se utiliza la doctrina de

\footnotetext{
${ }^{27}$ Como lo indicó el propio juez Holmes en el caso en que la Corte Suprema de Estados Unidos formuló por primera vez la doctrina de la expropiación regulatoria, "el gobierno apenas podría continuar si es que tuviera que indemnizar por cada modificación regulatoria realizada que disminuyera el valor de la propiedad", ver Pennsylvania Cal Company v. Mahon, 260 U.S. 393, 413, 11 de diciembre de 1922 ("Government hardly could go on if, to some extent, values incident to property could not be diminished without paying for every such change in the general law").

${ }^{28}$ Como sucede con las constituciones de la generalidad de los países, la de Chile no contempla garantías frente a los impactos de la regulación, sino que solo prevé la institución de la expropiación, ver Guiloff, Matías, "La expropiación regulatoria: Una doctrina impertinente para controlar la imposición de límites al derecho de propiedad privada en la Constitución chilena", Ius et Praxis, 2018, Vol. 24, n 2, pp. 276-277. Para una descripción y análisis acabados de la regulación de esta materia en diversas Constituciones, ver en general VAN DER WALT, A.J., Constitutional property clauses, Juta, Ciudad del Cabo, 1999.

${ }^{29}$ Sobre la potestad configuradora, ver GuILOFF y SALGADO, cit. (n. 8), pp. 512-513.
} 
la igualdad ante las cargas públicas para reparar lo que se considera "un accidente jurídico involuntario, casual y probablemente innecesario para alcanzar el objetivo que se había trazado la autoridad". ${ }^{30}$ Similarmente, en el "caso del ejemplar gratuito", el Tribunal Constitucional alemán admitió que ciertas regulaciones del derecho de propiedad que no son expropiatorias, pueden ser inconstitucionales en su aplicación a un supuesto concreto, por implicar una carga desproporcionada que vulnera la igualdad ante la ley. ${ }^{31}$ Para el contexto chileno, en caso que se aplique de manera correcta (es decir, analizando la compatibilidad entre la Constitución y la norma legal impugnada en su aplicación a una configuración fáctica concreta, en vez de evaluar si esta norma se conforma con la Constitución prescindiendo en el análisis de las repercusiones que genera su aplicación a la situación concreta), la institución de la inaplicabilidad por inconstitucionalidad también puede ser especialmente idónea para lidiar con estos efectos inconstitucionales imprevistos. ${ }^{32}$

¿Qué sucede con aquellas consecuencias patrimoniales que son previstas y queridas por el legislador al momento de diseñar una reforma? Como es evidente, adaptarse a estas cargas puede implicar un ajuste difícil para algunos o derechamente imposible para otros. ${ }^{33}$ Pero, por sí solo, ese impacto patrimonial no transforma a este problema político (en el sentido que se refiere a la distribución de los costos y beneficios de una modificación legal) en uno jurídico. ${ }^{34}$ Por supuesto, el análisis cambia para aquellas situaciones excepcionales donde lo que origina uno de esos costos es una intervención precisa sobre una posición efectivamente amparada mediante el derecho de propiedad -la expropiación-, o en las que la distribución de

\footnotetext{
${ }^{30}$ Valdivia, José Miguel, “¿Es justo que el Estado indemnice a quienes tienen prohibido explotar sus bosques de araucaria?", en: Universidad SANTo Tomás (Eds.), La responsabilidad del Estadoadministración, UST, Santiago, 2006, p. 1377.

${ }^{31}$ LuBENS, Rebecca, "The social obligation of property ownership: a comparison of german and US law", Arizona Journal of International \& Comparative Law, 2007, Vol. 24, № 2, pp. 410-411.

${ }^{32}$ Para esta comprensión de la inaplicabilidad por inconstitucionalidad, ver GómEz, Gastón, Las sentencias del Tribunal Constitucional y sus efectos sobre la jurisdicción ordinaria. Eds. Universidad Diego Portales, Santiago, 2013, pp. 19-20.

${ }^{33}$ Sobre los costos de las transiciones legales y su distribución, ver en general: TreBILCOCK, Michael, Dealing with Losers: The Political Economy of Policy Transitions, Oxford University Press, New York, 2014.

${ }^{34}$ Ponce de LeÓn, cit. (n. 9), p. 447
} 
cargas y beneficios obedece a un patrón arbitrario. ${ }^{35}$

Si no se dan esos supuestos, hay buenas razones para calificar a esas cargas como costos que entraña el hecho de vivir en una comunidad donde el marco jurídico debe irse ajustando para dar cuenta de los cambios que se vayan generando en ella. Ciertamente, como se resaltará en la conclusión, el legislador puede ser sensible a los argumentos de justicia y equidad relativos a las dificultades que la adaptación a una nueva realidad regulatoria puede generar, ${ }^{36}$ y establecer mecanismos de mitigación de costos transicionales. ${ }^{37}$ Pero -cabe ser majadero en esto- si no lo hace, no está cometiendo infracción constitucional alguna.

Habiendo descrito la concepción absoluta y las preocupaciones que la fundamentan, analicemos ahora un ejemplo de su aplicación al momento de discutirse un ajuste a una posición indudablemente amparada mediante un derecho de propiedad, como lo es un derecho de aprovechamiento de aguas. La modificación específica a la que aludiremos se refiere al establecimiento de la caducidad por no uso de estos derechos, en el proyecto de ley de reforma al Código de Aguas que, luego de 13 años de discusión parlamentaria, se materializó en la Ley No 20.047. ${ }^{38}$ Para cumplir el propósito central de esta propuesta de modificación legislativa (restituir el carácter de bien nacional de uso público a las aguas ${ }^{39}$ ), el mensaje del proyecto de ley contemplaba como instrumento central esta caducidad, la que se produciría en el evento

\footnotetext{
${ }^{35}$ PonCE DE LeÓN, cit. (n. 9), pp. 447-448. Como se ha sugerido, ello se debe a que, en la medida que evidencian un patrón sistemático, estas distribuciones arbitrarias de cargas patrimoniales pueden ser particularmente desmoralizantes para la ciudadanía, ver Michelman, cit. (n. 5), p. 1214. Sin embargo, esa misma desmoralización se puede generar por la entrega de beneficios o privilegios exorbitantes, los que pueden llegar a vulnerar la igualdad ante la ley, tal como se argumentó en el voto de minoría suscrito por los Ministros Carmona, Fernández y García, de la sentencia en que se efectuó el control preventivo de la Constitucionalidad de la Ley $\mathrm{N}^{\circ} 20.657$, que reformó a la Ley de Pesca. V. Tribunal Constitucional, rol 2.386-12, sentencia de 23 de enero de 2012 (considerandos 26 a 30). Para un análisis de estos beneficios o privilegios, en general, Guiloff, cit. (n. 19).

${ }^{36}$ Para un acabado análisis acerca de la incidencia de las argumentaciones de justicia y equidad al establecer o modificar regímenes que regulan el acceso y uso de los recursos naturales, ver en general RaYmond, Leigh, Private rights on public resources, Routledge, Washington, 2003.

${ }^{37}$ Tales como la continuidad de vigencia, la gradualidad y la misma indemnización, sea monetaria o no. Sobre estos mecanismos, ver Kaplow, Louis, "Transition Policy: A Conceptual Framework", Journal of Contemporary Legal Issues, 2003, $\mathrm{n}^{\circ}$ 13, p. 186.

${ }^{38}$ Esta descripción se basa en Guiloff, cit. (n. 4), pp. 120-121.

${ }^{39}$ Véase Biblioteca del Congreso Nacional (Eds.), Historia de la Ley 20.017, modifica el Código de Aguas, BCN, Santiago, 2005, disponible en línea: https://www.bcn.cl/historiadelaley/nc/historiade-la-ley/5838/ (Fecha de visita: 12 de mayo de 2021), p. 6.
} 
que el titular de uno de estos derechos no lo utilizara efectivamente dentro del plazo de 5 años o en aquel que se señalara en la respectiva concesión. Mediante este mecanismo se buscaba incentivar el uso efectivo de las aguas por parte de los titulares de derechos de aprovechamiento, dada la evidencia de altos niveles de especulación y la carencia de instrumentos que fueran idóneos para lidiar con ella que se evidenciaba en el Código de Aguas. ${ }^{40} \mathrm{La}$ elección de dicho mecanismo no parecía para nada caprichosa, ya que era el mismo que se había previsto para el cumplimiento de análoga función en los Estados del oeste de Estados Unidos, ${ }^{41}$ así como en la legislación española de aguas y en el propio Código de Aguas chileno de 1952.

Unos pocos meses después, y antes que el proyecto siquiera hubiese sido discutido en general, el gobierno presentó una indicación sustitutiva. Ella limitó el ámbito de aplicación inicialmente previsto para la caducidad por no uso, haciéndola procedente únicamente respecto de los derechos que se otorgasen una vez que hubiese entrado en vigencia el proyecto de ley en discusión. ${ }^{42}$ No hay mayores indicios en la historia legislativa de las razones por las que el gobierno efectuó esta modificación. Las fuentes secundarias, sin embargo, indican que se montó una feroz oposición en contra del establecimiento de esta caducidad, la que se fundó en considerar que ella atentaba en contra del derecho de propiedad privada. ${ }^{43}$ Además -y como se enfatizará posteriormente, es muy relevante- recalcan que en el Senado el gobierno no contaba con los votos necesarios para la aprobación de esta reforma. ${ }^{44}$

Unos pocos años después el gobierno optó por desistir completamente de la caducidad por no uso, sustituyéndola por un inaudito mecanismo denominado patente por no uso. ${ }^{45}$ Este instrumento resultaba bastante menos amenazante para los titulares de derechos de aprovechamiento, en la medida que no castigaba con su pérdida la no utilización de estos dentro de un plazo. Para cumplir la misma función de incentivar el uso efectivo

\footnotetext{
${ }^{40}$ Historia de la Ley 20.017, cit. (n. 39), p. 5.

${ }^{41}$ Ver TARLOCK, Dan, "The Changing Meaning of Water Conservation in the West", Nebraska Law Review, 1987, Vol. 66, № 1, p. 152.

${ }^{42}$ Historia de la Ley 20.017, cit. (n. 39), p. 17.

${ }^{43}$ Véase BAUER, Carl, Siren song: Chilean water law as a model for international reform, Routledge, Washington, 2004, p. 57.

${ }^{44}$ BAuer, cit. (n. 43), p. 66.

${ }^{45}$ Historia de la Ley 20.017, cit. (n. 39), p. 22.
} 
de las aguas que la caducidad, establecía el deber de pagar una patente por parte de quien no lo hiciera. Solo en el evento que esta patente tampoco fuera pagada se establecía como consecuencia la pérdida del derecho. Sin embargo, a pesar que imponía una carga bastante menos significativa que la caducidad, la patente por no uso fue objeto de un requerimiento ante el Tribunal Constitucional que finalmente fue rechazado. ${ }^{46}$

Sin embargo, este no fue el final de la historia: tuvieron que pasar otros ocho años de discusión -sobre todo en el Senado- para que la patente fuera finalmente aprobada. La historia legislativa da cuenta que para lograr la aprobación del proyecto el gobierno debió hacer varias concesiones. Una de ellas fue la reducción de la progresión que se había establecido para la tasa de la patente, para el supuesto que los derechos no fueran utilizados por largos períodos. Dicha regla se había contemplado para desincentivar la especulación que se producía con estos en la actividad de generación hidroeléctrica, y en ella se establecía específicamente que, en el evento que transcurrieran más de diez años de no uso, el valor de la patente aumentaría veinticinco veces. ${ }^{47}$

Sin embargo, a raíz de la oposición que suscitó y de la circunstancia que el gobierno no contaba con los votos necesarios para aprobar el proyecto en el Senado, ese esquema de progresión fue reducido, disponiéndose que al cabo del aludido lapso el valor de la patente solo aumentaría en cuatro veces. ${ }^{48}$ En palabras del Subsecretario de Obras Públicas de la época, ello obedeció a la posibilidad que el esquema de progresión primitivamente contemplado fuese declarado inconstitucional por el Tribunal Constitucional. ${ }^{49}$ Como se puede apreciar, la sola posibilidad que la disposición fuera declarada inconstitucional fue la que llevó a morigerar los potenciales impactos sobre el derecho de propiedad privada de la reforma en debate.

El caso anteriormente descrito sugiere que la interpretación efectuada por el Congreso sobre el alcance del Derecho de propiedad privada se encuentra fuertemente influida por la concepción absoluta acerca de este. Desde luego porque parte de la premisa que el legislador cuenta con un margen reducido para imponerle limitaciones u obligaciones derivadas de

\footnotetext{
${ }^{46}$ Véase Tribunal Constitucional, 1 de octubre de 1997, Rol 260.

${ }^{47}$ Historia de la Ley 20.017, cit. (n. 39), pp. 35-36.

${ }^{48}$ Historia de la Ley 20.017, cit. (n. 39), p. 928.

${ }^{49}$ Ibídem.
} 
su función social. Sin embargo, y como se ha visto, al menos en lo que se refiere al texto constitucional, la situación es más bien la contraria: esta habilita al legislador para imponer las cargas anteriormente descritas para dar resguardo a cuánto exijan los elementos que ella comprende.

Por tanto, la explicación más intuitiva que se puede ofrecer para justificar que al interpretar el alcance de los derechos de propiedad sobre los derechos de aprovechamiento de aguas el Congreso haya sido tan influido por la concepción absoluta, es que esto se debió a una cuestión puramente política: simplemente no estaban los votos. Esta explicación sería persuasiva, qué duda cabe, para un ordenamiento constitucional donde no se contemplara la posibilidad que el tribunal constitucional pudiera efectuar un control preventivo de la constitucionalidad de las leyes, previo requerimiento de un grupo reducido de parlamentarios. Como se sabe, el chileno no es uno de esos ordenamientos. El control preventivo se encuentra previsto, y contrariamente a lo que se podría pensar en abstracto, no solo impacta a los proyectos de ley que son efectivamente objeto de un requerimiento, sino que también a todos en cuya tramitación se suscite una discusión acerca de la constitucionalidad de una de sus disposiciones. La explicación más detallada de las implicancias de este último punto para la protección del derecho de propiedad privada es el objeto de la próxima sección.

\section{LAS CONCEPCIONES Y EL AMBIENTE INSTITUCIONAL EN QUE SE DEBATEN}

Habiendo dado cuenta de la singularidad que presenta el ambiente institucional chileno en el que se discute acerca de las eventuales afectaciones al derecho de propiedad privada por parte de una propuesta de modificación legal, resta por explicar cómo ella puede determinar la incidencia de una determinada concepción relativa a este derecho, como es el caso de la extendida y la absoluta, en el debate legislativo. Dado que el control preventivo es una eventualidad cuya ocurrencia, dado el bajo número de parlamentarios que la Constitución exige para activarlo (tan solo la cuarta parte de los miembros de cada cámara), no es para nada improbable, lo que termina sucediendo es que el contenido de las disposiciones de los proyectos de ley que generan más cuestionamientos constitucionales se 
terminan negociando "bajo la sombra del Tribunal Constitucional", ${ }^{50}$ es decir, bajo la amenaza que si no se hacen las concesiones reclamadas por quienes formulas las objeciones, el proyecto será llevado ante el Tribunal Constitucional. Para quién está promoviendo el respectivo proyecto de ley (en nuestro sistema, por regla general, el gobierno), es razonable darle algún peso a esta amenaza considerando la biografía de este tribunal, que viene dada por su jurisprudencia. ${ }^{51}$ En breve, la existencia del control preventivo genera una dinámica en la discusión legislativa que fortalece el peso de las concepciones acerca de las instituciones constitucionales de aquellos que buscan resistir la aprobación de una reforma (como sucede precisamente con las y los operadores que invocan la concepción extendida y la absoluta del derecho de propiedad privada).

El análisis contenido en el párrafo anterior resalta el rol que juega la sola posibilidad del control preventivo en la interpretación que haga el Congreso acerca del alcance del Derecho de propiedad privada, pero no ofrece explicación alguna sobre por qué el Tribunal Constitucional utilizaría algunas de estas concepciones. Esta justificación parece aún más necesaria si se considera, como se ha enfatizado, que ambas no se avienen con la regulación del derecho de propiedad privada contenida en las normas constitucionales. En los siguientes párrafos se proporciona una explicación tentativa para este fenómeno.

\footnotetext{
${ }^{50} \mathrm{La}$ idea que algunas reglas o decisiones sirven para estructurar las negociaciones que conducen a la adopción de un acuerdo es sugerida para el ámbito del derecho de Familia por MNOoKIn, Robert; Kornhauser, Lewis, "Bargaining in the Shadow of the Law: The Case of Divorce", Yale Law Journal, 1979, $\mathrm{n}^{\circ}$ 88. Debo esta referencia a Alberto Coddou.

${ }^{51}$ Unos pocos meses después de la entrada en funcionamiento del Congreso, y como se describió anteriormente, el Tribunal Constitucional incidió sobre la tramitación de la Ley de Pesca al determinar que la reforma que se buscaba introducir requería ser aprobada con un quórum de ley de quórum calificado, ver Tribunal Constitucional, sentencia de 3 de diciembre de 1990, Rol 115, Posteriormente, conociendo de un requerimiento de inconstitucionalidad formulado por un grupo de parlamentarios, el Tribunal Constitucional declaró la inconstitucionalidad de la norma que venía a poner fin a la facultad de las instituciones bancarias de capitalizar dividendos, en el caso de la deuda subordinada, ver Tribunal Constitucional, sentencia de 10 de febrero de 1995, Rol 207. Algunos años después, este tribunal acogió otro de estos requerimientos y estableció la inconstitucionalidad de la norma que contemplaba la obligación de las administradoras de fondos de pensiones de traspasar los fondos que se encontraran en la cuenta individual del afiliado a las compañías de seguros, en caso que este optara por pensionarse bajo el sistema de renta vitalicia, ver Tribunal Constitucional, 21 de agosto de 2001, Rol No 334-2001. Más recientemente, el Tribunal Constitucional, acogiendo nuevamente un requerimiento de un grupo de parlamentarios, declaró inconstitucional la titularidad sindical que se había previsto en la reforma laboral impulsada durante el segundo gobierno de Michelle Bachellet, ver Tribunal Constitucional, 11 de agosto de 2016, Rol No 3112-2016.
} 
Para explicar la reserva de ley -otra institución regulada en la constitución que ha generado un gran debate- la literatura releva como su confusa regulación se explica por la confluencia de dos comprensiones diversas acerca de esta reserva (la germana y la francesa). ${ }^{52}$ Tratándose de la propiedad sucede algo parecido pero no del todo análogo, en cuanto respecto de esta última las dificultades interpretativas no derivan del hecho que las normas que la regulan se encuentren influidas por tradiciones legales diversas, sino que de la circunstancia que dos tradiciones, también distintas, ejercen influencia sobre las normas y la cultura jurídica que las interpreta, respectivamente. En efecto, mientras las normas constitucionales mayoritariamente siguen la tradición constitucional europea continental en materia de propiedad privada (específicamente, la de Alemania y España), la cultura hace lo propio con la estadounidense.

A lo largo de este trabajo se han hecho varias menciones al contenido del artículo $19 \mathrm{~N}^{\circ} 24$, por lo que aquí solo se pondrá en evidencia cómo es que este se encuentra influido por la regulación alemana y española. La manera más nítida de ilustrar este punto es, nuevamente, mediante un contraste, en este caso el existente entre la regulación de la propiedad en la Constitución estadounidense y la alemana, y luego comparar la de la Constitución Política chilena con estas. Se parte haciendo este ejercicio entonces con la Constitución de Estados Unidos, cuya regulación de este derecho solo se limita a indicar que la propiedad privada no podrá ser destinada al uso público sin que se pague una compensación. Aun cuando la Constitución alemana también contiene una frase análoga en la regulación de la propiedad, esta indica además que el contenido y límites de la propiedad deberán ser establecidos por la ley, señalando adicionalmente que la propiedad genera obligaciones y que su uso también debe servir al interés público. Cómo es fácil de advertir, es la última consagración la que guarda más similitud con la contenida en la Constitución chilena, que no se limita a consagrar la institución de la expropiación para proteger la propiedad sino que también, y de manera elocuente, se refiere a la potestad del legislador para imponer limitaciones y obligaciones sobre esta. ${ }^{53}$

\footnotetext{
52 Ver en general: ZúÑIGA, Francisco, "Apostillas: ley y reglamento en la Jurisprudencia del Tribunal Constitucional (de la germanización al practicismo)", Revista Ius et Praxis, 2001, Vol. 7, n 2.

${ }^{53}$ Para un análisis más detallado sobre este contraste, ver Guiloff, cit. (n. 28), pp. 637-641.
} 
Tratándose de la cultura interpretativa ${ }^{54}$ puede afirmarse que, en materia de derecho de propiedad privada, existe una influencia de a lo menos tres tradiciones, sin perjuicio que en los hechos algunas tengan más impacto que otras. Por una parte, no son pocos los requerimientos de inconstitucionalidad y de inaplicabilidad por inconstitucionalidad que se basan en el supuesto basal de la doctrina estadounidense de la expropiación regulatoria: una regulación que va demasiado lejos deviene en (y debe ser tratada jurídicamente como) una expropiación. ${ }^{55}$ Similarmente, y de modo especialmente intenso, durante los últimos 15 años, no son pocas las publicaciones que describen y abogan por el uso de esta doctrina. ${ }^{56}$ Por otro lado, y como era de esperarse considerando la similitud existente entre los respectivos textos constitucionales, existen diversos trabajos que analizan la regulación constitucional de la propiedad en Chile sobre la base de categorías alemanas ${ }^{57}$ y españolas. ${ }^{58}$

Finalmente, pero no menos relevante que ninguna de las anteriores, está la tradición chilena. El objeto principal de esta es el alcance que ha de

\footnotetext{
${ }^{54}$ Por este término me refiero a las diversas teorías que se ocupan en un sistema legal en un momento dado, para fundamentar una manera precisa y singular de interpretar una institución legal -en este caso el derecho de propiedad privada- en el razonamiento que lleva a la resolución un caso concreto donde esta se encuentra implicada, ver EsQuirol, Jorge, "The Turn to Legal Interpretation in Latin America", American University International Law Review, 2011, Vol. 26, No 4, pp. 1037-1038.

${ }^{55}$ Solo por nombrar algunos, ver Tribunal Constitucional, rol No 245-1996 y rol No 246-1996 (acumuladas), de 2 de diciembre de 1996 (Caso Playas I); Tribunal Constitucional, rol No 505-2006, de 6 de marzo de 2007 (Caso Eléctricas) y Tribunal Constitucional, Rol № 2684-2014-INA, de 10 de septiembre de 2015 (Caso Curtidos Bas).

${ }^{56}$ Ver en general: Delaveau, Rodrigo, "La regulación expropiatoria en la jurisprudencia norteamericana", Revista Chilena de Derecho, 2006, Vol. 33, N 3; Fermandois, Arturo, "Curtidos Bas y expropiación regulatoria: elevando el estándar constitucional para cargas gravosas a la propiedad", en LiBERTAD Y Desarrollo (Eds.), Sentencias destacadas 2015, Ediciones Libertad y Desarrollo, Santiago, 2015, pp. 263-291; y GARCÍA, José Francisco, "El tribunal constitucional y el uso de "tests": una metodología necesaria para fortalecer la revisión judicial económica", Revista Chilena de Derecho, 2011, Vol. 38, $\mathrm{N}^{\circ} 1$, pp. 116-133.

${ }^{57}$ Ver en general: AldunATE, Eduardo, "Deficiencias en la argumentación jurídica. Comentario crítico al fallo del Tribunal Constitucional librado en la causa rol No 207", Revista de Derecho - P. Universidad Católica de Valparaíso, 1995, Vol. 16; Aldunate, Eduardo; Fuentes, Jessica, "El concepto de derecho de propiedad en la jurisprudencia constitucional chilena y la teoría de las garantías de instituto", Revista de Derecho - P. Universidad Católica de Valparaíso, 1997, Vol. 18; Aldunate, Eduardo, "Limitación y Expropiación: Scilla y Caribdis de la dogmática constitucional de la propiedad", Revista Chilena de Derecho, 2006, Vol. 33, N 2; CorDERo, Eduardo, "La dogmática constitucional de la propiedad en el Derecho Chileno", Revista de Derecho Universidad Austral de Chile, 2006, Vol. 19, $\mathrm{N}^{\circ} 1$; Ponce De León, Viviana, "La noción de carga pública y su función en la jurisprudencia del Tribunal Constitucional", Revista Chilena de Derecho, 2015, Vol. 42, N 3.
}

${ }^{58}$ Ver en general, RaJevic, cit. (n. 6). 
atribuírsele a la función social de la propiedad y los límites a esta, aspecto sobre el cual existen dos corrientes. Están, por una parte, quienes realzan la importancia de esta y defienden su potencialidad para ir configurando y delimitando el derecho de propiedad privada. ${ }^{59} \mathrm{Y}$ también los que, por la otra, no sin cierta nostalgia por los textos constitucionales que consagraban la inviolabilidad de la propiedad, dedican esfuerzos a tipificar e interpretar restrictivamente los supuestos en que se puede invocar la función social ${ }^{60} \mathrm{o}$ a establecer los límites que esta debe respetar. ${ }^{61}$

Dado que se trata de un planteamiento dogmático que se erige sobre el supuesto de la existencia de límites a la regulación legislativa de la propiedad, y probablemente también por el prestigio del sistema legal en que se origina, la tesis de la expropiación regulatoria resulta particularmente atractiva para la corriente de la cultura chilena que busca confinar la potestad del legislador para configurar e imponer limitaciones a la propiedad privada conforme a su función social. ${ }^{62}$ De esta forma, se produce algo así como un matrimonio por conveniencia entre la cultura interpretativa estadounidense y esta vertiente de la chilena para resguardar la propiedad frente a potenciales intervenciones legislativas. Esta unión o coalición llega a a ejercer influencia sobre la adjudicación constitucional en la medida que varios de sus exponentes llegan a ser ministros del tribunal constitucional o bien abogados que litigan recurrentemente en este. Y su impacto se refleja en que algunos fallos del tribunal constitucional aluden explícitamente a la doctrina de la expropiación regulatoria y argumentan su compatibilidad con

\footnotetext{
${ }^{59}$ Ríos, Lautaro, "El Principio Constitucional de la Función Social de la Propiedad", Revista de Derecho y Jurisprudencia, 1986, Vol. 84, N² 2, p. 121; NovoA, Eduardo, El Derecho de Propiedad Privada. Concepto, evolución y crítica. Centro de Estudios Políticos Latinoamericano Simón Bolívar, Santiago, 1989, $2^{\mathrm{a}}$ edición, p. 112.

${ }^{60}$ Evans, Enrique, Los Derechos Constitucionales, Editorial Jurídica de Chile, Santiago, 2004, T. II, p. 378.

${ }^{61}$ Véase en general: MoноR, Salvador, "Taxonomía de las limitaciones al dominio y derecho de indemnización", Revista Chilena de Derecho, 1989, Vol. 16, n² 2; y CEA, José Luis, "Delimitación y privación del dominio en la Constitución de 1980", en AA.VV., XVIII Jornadas Chilenas de Derecho Público, Universidad de Concepción, Concepción, 1988, pp. 55-68.

${ }^{62} \mathrm{Sin}$ embargo, la aplicación de esta tesis por parte de la jurisprudencia ha sido sumamente contradictoria, al punto que uno de los trabajos más citados sobre la expropiación regulatoria no duda en sostener que se trata de una doctrina confusa, llegando incluso a afirmarlo en el título del respectivo artículo. Rose, Carol, "Mahon reconstructed: Why the Takings Issue is Still a Muddle", Southern California Law Review, 1984, Vol. 57, n 4. El título del aludido trabajo es porqué el asunto de la expropiación regulatoria sigue siendo un embrollo (a muddle).
} 
la regulación constitucional chilena del derecho de propiedad privada. ${ }^{63}$

V. EPÍLOGO: ¿QUÉ SE PUEDE HACER EN UNA NUEVA CONSTITUCIÓN Y EN LA PRÁCTICA POLÍTICA QUE ORIGINE PARA QUE EL RESGUARDO DEL DERECHO DE PROPIEDAD PRIVADA NO PONGA EN RIESGO LA SUSTENTABILIDAD DE LA COMUNIDAD POLÍTICA?

Como ha quedado en evidencia, la robustez de la protección de la propiedad privada en la Constitución Política de 1980 no deriva tanto de la regulación contenida en la respectiva cláusula, sino que más bien del principal dispositivo que se consagró en esta para neutralizar la potestad legislativa en general, el control preventivo por parte del tribunal constitucional. $\mathrm{Su}$ existencia incide en las discusiones que afectan a posiciones económicas, sea que se encuentren efectivamente amparadas por el derecho de propiedad o no, de una manera bien precisa: haciendo probable que prevalezcan las argumentaciones constitucionales que defienden la intangibilidad de esas situaciones. Ello deriva en que la concepción extendida y absoluta del derecho de propiedad se terminen imponiendo en el debate, no obstante su discordancia con el texto constitucional.

La existencia de esta cultura en materia de propiedad que funde elementos de la tradición constitucional chilena con la estadounidense y el éxito que ha tenido al ser invocada al discutir reformas en el Congreso, sugieres dos aspectos importantes para el proceso constituyente en curso. El primero de ellos es un mensaje de cautela: La interpretación que se le otorgue en la práctica constitucional que se avecina al derecho de propiedad privada, no va a depender solo de lo que diga la respectiva cláusula, sino que también de las interpretaciones sobre esta que vaya formulando la cultura. Relacionado con lo anterior, el segundo es que, al menos en el corto plazo, no es razonable suponer que la cultura hasta ahora predominante en el debate legislativo, cambiará. Las ideas sobre las principales categorías de la propiedad, tales como la reserva legal, la función social o su contenido esencial, que se instalaron en la cabeza de los operadores jurídicos (entre

\footnotetext{
${ }^{63}$ Ver Tribunal Constitucional, 6 de marzo de 2007, Rol № 505-2006, considerando vigésimo segundo (Caso Eléctricas), y Tribunal Constitucional, 29 de enero de 2014, Rol N 2299-2012-INA, considerando 9 (Caso Santa Beatriz).
} 
otras y otros, abogados, jueces, profesores y los propios parlamentarios), muy difícilmente se modificarán en el corto. Por lo mismo, a nadie debiera sorprender que en la eventualidad que en la nueva Constitución se consagre una regulación incompatible con las concepciones de la propiedad analizadas en este trabajo, ellas sigan siendo invocadas.

Sin embargo, pese a lo anteriormente señalado y a que los derechos de propiedad siempre son más o menos pegajosos o difíciles de modificar, ${ }^{64}$ el nuevo texto constitucional sí puede generar una diferencia significativa en lo que concierne a la práctica del derecho de propiedad con respecto a su antecesor. Ésta se refiere a la configuración del ambiente institucional en que se darán las discusiones relativas al sentido y alcance del derecho de propiedad al momento de debatir una modificación legal que pueda incidir sobre este. Durante la vigencia de la Constitución Política de 1980, debido a la dinámica que genera la eventualidad de un control preventivo altamente probable, el proceso legislativo ha sido la mejor defensa del derecho de propiedad privada. Pero es justamente en su singular eficacia donde radica su principal problema.

El control preventivo no solo evita el establecimiento de excesos regulatorios, sin que también, como ha ilustrado la referencia a la reforma del Código de Aguas, de ajustes de alcance limitado. Esto último es particularmente problemático porque si se considera que rara vez, sino nunca, el legislador tiene información completa al momento de establecer un esquema regulatorio, además de los cambios que habitualmente se producen en la realidad debido a factores geográficos, climáticos, sociales y económicos, es razonable que se haga necesario ir introduciendo ajustes a los marcos legales de tiempo en tiempo. Sin embargo, ello se vuelve improbable cuando existe un dispositivo tan eficaz para resistir cambios como lo es el control preventivo.

Lo anterior ilustra que el actual proceso constituyente sí puede decidir algo relevante que puede tener repercusiones determinantes en el rol que cumple el derecho de propiedad privada en la articulación de la tensión entre estabilidad y cambio: eliminar el control preventivo por parte del tribunal constitucional. En la medida que la posibilidad del control preventivo, de

\footnotetext{
${ }^{64}$ V. MerriLl, Thomas, "The Demsetz Thesis and the Evolution of Property Rights", Journal of Legal Studies, 2002, Vol. 31, № 4, p. S337; y Doremus, Holly, "Climate Change and the Evolution of Property Rights”, U.C. Irvine Law Review, 2011, Vol. 1, n 4, pp. 1099-1100.
} 
un veto definitivo, no se encuentre latente en la discusión, es más probable que debatan en igualdad de condiciones las diversas concepciones o culturas interpretativas respecto al sentido y alcance del derecho de propiedad privada. Esto evitará que para aprobar los ajustes a los marcos legales que el tiempo demuestre necesarios, se deban introducir a estos concesiones y mitigaciones exageradas, que limiten su ámbito de aplicación, así como su funcionalidad para cumplir los objetivos que procuran satisfacer. ${ }^{65}$

Adicionalmente, $\mathrm{y}$ ahora en lo relativo a la práctica constitucional que se puede generar bajo una nueva constitución, también es importante que el legislador, tanto por la influencia que las concepciones sobre la propiedad ejercen sobre los debates legislativos como por lo difícil que resulta intervenir sobre realidades materiales que son fuentes de importantes utilidades económicas, sea cuidadoso al momento de configurar las regulaciones que permiten la generación de éstas. En Derecho Administrativo, en lo estrictamente referido a los actos administrativos de efectos favorables, se dice que estos son "fáciles de dictar, pero difíciles de modificar o dejar sin efecto". ${ }^{66}$ Como evidencia este trabajo, lo mismo vale para las disposiciones de rango legal que generan beneficios económicos. Aun cuando los reclamos de justicia y equidad derivados de un cambio en el régimen regulatorio de una actividad determinada dan cuenta de un problema político, lo cierto es que, valiéndose de la concepción extendida y la absoluta, los operadores lo pueden presentar como uno jurídico. Por ello, es importante que el legislador tome nota de esta situación y sea lo más concreto posible al momento de articular las reglas que determinan los horizontes de inversión, generadores de esas realidades materiales en las cuales luego es tan difícil intervenir.

Por último, y esto también se refiere a la práctica legislativa, es importante que, más allá de lo que la Constitución regule y consiguientemente defina como un problema jurídico, el legislador vaya adquiriendo destrezas en la identificación de los costos que pueden generar las modificaciones que debate, para así poder evaluar si corresponde establecer mecanismos de mitigación. No todas y todos los habitantes y agentes de una comunidad política tienen las mismas capacidades para adaptarse a los cambios que

${ }^{65}$ Stone Sweet, Alec, "Rules, Dispute Resolution and Strategic Behavior", Journal of Theoretical Politics, 1998, Vol. 10, pp. 329-330; Revesz, Richard; Westfahl Kong, Allison, "Regulatory Change and Optimal Transition Relief", Northwestern University Law Review, Vol. 105, n 4, p. 464.

${ }^{66}$ VAldivia, José Miguel, Manual de Derecho Administrativo, Tirant Lo Blanch, Madrid, 2018, p, 213. 
generan las modificaciones legales, y la legislación es un instrumento privilegiado para poder identificar aquellas situaciones y establecer mecanismos de mitigación de los costos transicionales (tales como, entre otros, gradualidad, continuidad de vigencia y compensaciones, sean monetarias o no) en los casos que existan consideraciones de justicia y equidad realmente persuasivas. En el desarrollo de esta habilidad y criterio también se juega una parte importante de la sustentabilidad de una comunidad política.

\section{BIBLIOGRAFÍA CITADA}

\section{a) Doctrina}

Ackerman, Bruce, Private Property and the Constitution, Yale University Press, New Haven, 1977.

Aldunate, Eduardo, "Deficiencias en la argumentación jurídica. Comentario crítico al fallo del Tribunal Constitucional librado en la causa rol No 207", Revista de Derecho - P. Universidad Católica de Valparaíso, 1995, Vol. 16.

Aldunate, Eduardo; Fuentes, Jessica, "El concepto de derecho de propiedad en la jurisprudencia constitucional chilena y la teoría de las garantías de instituto", Revista de Derecho - P. Universidad Católica de Valparaíso, 1997, Vol. 18.

Aldunate, Eduardo, "Limitación y Expropiación: Scilla y Caribdis de la dogmática constitucional de la propiedad", Revista Chilena de Derecho, 2006, Vol. $33, \mathrm{~N}^{\mathrm{o}} 2$.

BAUER, Carl, Siren song: Chilean water law as a model for international reform, Routledge, Washington, 2004.

CEA, José Luis, "Delimitación y privación del dominio en la Constitución de 1980", en AA.VV., XVIII Jornadas Chilenas de Derecho Público, Universidad de Concepción, Concepción, 1988, pp. 55-68.

Cole, Daniel; Grossman, Peter, "The meaning of property rights: Law versus economics”, Land Economics, 2002, Vol. 78, N 3.

CORDERO, Eduardo, "La dogmática constitucional de la propiedad en el Derecho Chileno", Revista de Derecho Universidad Austral de Chile, 2006, Vol. $19, \mathrm{~N}^{\circ} 1$.

DAGAN, Hanoch, "Restitution and slavery: on incomplete commodification, intergenerational justice, and legal transitions", Boston University Law Review, $2004, n^{\circ} 84$.

Delaveau, Rodrigo, "La regulación expropiatoria en la jurisprudencia norteamericana", Revista Chilena de Derecho, 2006, Vol. 33, №3. 
Doremus, Holly, "Takings and Transitions", Journal of Land Use and Environmental Law, 2003, Vol. 19, ${ }^{\circ} 1$.

Doremus, Holly, "Climate Change and the Evolution of Property Rights", U.C. Irvine Law Review, 2011, Vol. 1, $\mathrm{n}^{\circ} 4$.

Esquirol, Jorge, "The Turn to Legal Interpretation in Latin America", American University International Law Review, 2011, Vol. 26, No 4.

Evans, Enrique, Estatuto constitucional del derecho de propiedad en Chile, Editorial Jurídica de Chile, Santiago, 1967.

Evans, Enrique, Los Derechos Constitucionales, Editorial Jurídica de Chile, Santiago, 2004, Tomo II.

Fermandois, Arturo, "Curtidos Bas y expropiación regulatoria: elevando el estándar constitucional para cargas gravosas a la propiedad", en LiBERTAD Y Desarrollo (Eds.), Sentencias destacadas 2015, Ediciones Libertad y Desarrollo, Santiago, 2015, pp. 263-291.

FrIED, Barbara, The progressive assault on laissez faire. Robert Hale and the first law and economics movement, Harvard University Press, Cambridge, 1998.

García, José Francisco, "El tribunal constitucional y el uso de "tests": una metodología necesaria para fortalecer la revisión judicial económica", Revista Chilena de Derecho, 2011, Vol. 38, $\mathrm{N}^{\circ} 1$.

Gómez, Gastón, Las sentencias del Tribunal Constitucional y sus efectos sobre la jurisdicción ordinaria, Eds. Universidad Diego Portales, Santiago, 2013.

Guiloff, Matías, "Ley de Pesca: Explicando un regalo regulatorio", Anuario de Derecho Público UDP, 2013, $\mathrm{n}^{\circ} 1$.

Guiloff, Matías, "El estatuto constitucional de la propiedad: una mirada ex ante”, en: ChíA, E.; Quezada, F. (Eds.) Propuestas para una nueva Constitución (Originada en democracia), Instituto Igualdad, Santiago, 2015.

Guiloff, Matías, "Elija cuál derecho de propiedad privada se protege. La precisión de las normas legales que establecen limitaciones a la propiedad privada, a propósito de los fallos Molinera del Norte y curtido Bas", Anuario de Derecho Público UDP, 2016, $\mathrm{n}^{\circ} 1$.

Guiloff, Matías, "La expropiación regulatoria: Una doctrina impertinente para controlar la imposición de límites al derecho de propiedad privada en la Constitución chilena", Revista Ius et Praxis, 2018, Vol. 24, n 2.

Guiloff, Matías; Salgado, Constanza, "Derecho de propiedad", en: Contreras, P.; Salgado, C. (Eds.), Curso de Derechos Fundamentales, Tirant Lo Blanch, Santiago, 2020.

GuZmán BRito, Alejandro, Las cosas incorporales en la Doctrina y en el Derecho positivo, Editorial Jurídica de Chile, Santiago, 1995.

Horwitz, Morton, The transformation of American law, 1870-1960: The Crisis of Legal Orthodoxy, Oxford University Press, Oxford, 1994.

JANA, Andrés; Marín, Juan Carlos, Recurso de protección y contratos, 
Editorial Jurídica de Chile, Santiago, 1996.

KAPLOw, Louis, "Transition Policy: A Conceptual Framework", Journal of Contemporary Legal Issues, 2003, $\mathrm{n}^{\circ} 13$.

LuBENs, Rebecca, "The social obligation of property ownership: a comparison of german and US law", Arizona Journal of International \& Comparative Law, 2007, Vol. 24, $\mathrm{N}^{\circ} 2$.

Luhmann, Niklas, "Operational Closure and Structural Coupling: the Differentiation of the Legal System", Cardozo Law Review, 1992, Vol. 13, n 5.

Matute, Claudio, Regulaciones Expropiatorias. Aplicabilidad al caso chileno, Legal Publishing, Santiago, 2014.

Merrill, Thomas, "The Demsetz Thesis and the Evolution of Property Rights”, Journal of Legal Studies, 2002, Vol. 31, № 2.

Michelman, Frank, "Property, Utility and Fairness: Comments on the Ethical Foundations of Just Compensation Law", Harvard Law Review, 1967, n 80.

MnOoKIn, Robert; Kornhauser, Lewis, "Bargaining in the Shadow of the Law: The Case of Divorce", Yale Law Journal, 1979, n 88.

Moнor, Salvador, "Taxonomía de las limitaciones al dominio y derecho de indemnización”, Revista Chilena de Derecho, 1989, Vol. 16, nº 2.

Nonet, Philippe; Selznick, Phillip, Law \& Society in Transition. Towards Responsive Law, Transaction Publishers, New Brunswick, 2008, 4ª edición.

North, Douglas, Institutions, institutional change and economic performance, Cambridge University Press, New York, 1991.

Novon, Eduardo, El Derecho de Propiedad Privada. Concepto, evolución y crítica, Centro de Estudios Políticos Latinoamericano Simón Bolívar, Santiago, 1989, $2^{\text {a }}$ edición corregida y aumentada.

PONCE DE LeÓN, Viviana, La problemática invocación a la confianza legítima como límite a la potestad legislativa, Estudios Constitucionales, 2014, año 12, $\mathrm{n}^{\circ} 1$.

PonCE DE León, Viviana, "La noción de carga pública y su función en la jurisprudencia del Tribunal Constitucional", Revista Chilena de Derecho, 2015, Vol. 42, $\mathrm{N}^{\circ} 3$.

RAJEvic, Enrique, "Limitaciones, reserva legal y contenido esencial de la propiedad privada", Revista Chilena de Derecho, 1996, Vol. 23, № 1.

RAYMOND, Leigh, Private rights on public resources, Routledge, Washington, 2003.

Revesz, Richard; WestFahl Kong, Allison, "Regulatory Change and Optimal Transition Relief", Northwestern University Law Review, Vol. 105, n 4, pp. 15811633.

Ríos, Lautaro, "El Principio Constitucional de la Función Social de la Propiedad", Revista de Derecho y Jurisprudencia, 1986, Vol. 84, № 2.

Rose, Carol, "Mahon reconstructed: Why the Takings Issue is Still a Muddle", Southern California Law Review, 1984, Vol. 57, n 4. 
SERkin, Christopher, "Penn Central take two", Notre Dame Law Review, 2017, Vol. 92, No 2.

Stone Sweet, Alec, "Rules, Dispute Resolution and Strategic Behavior", Journal of Theoretical Politics, 1998, Vol. 10, pp. 327-338.

TARLOCK, Dan, "The Changing Meaning of Water Conservation in the West", Nebraska Law Review, 1987, Vol. 66, № 1, pp. 145-174.

Trebilcock, Michael, Dealing with Losers: The Political Economy of Policy Transitions, Oxford University Press, New York, 2014.

VAldivia, José Miguel, “¿Es justo que el Estado indemnice a quienes tienen prohibido explotar sus bosques de araucaria?", en: UnIVERSIDAD SANTO TOMÁs (Eds.), La responsabilidad del Estado-administración, UST, Santiago, 2006, pp. 133-142.

Valdivia, José Miguel, Manual de Derecho Administrativo, Tirant Lo Blanch, Madrid, 2018. 1999.

Van Der Walt, A.J., Constitutional property clauses, Juta, Ciudad del Cabo,

Vergara, Alejandro, "La propietarización de los derechos", Revista de Derecho P. Universidad Católica de Valparaíso, 1992, Vol. 14.

WyMAn, Katrina, "Problematic private property: The case of New York Taxicab Medallions", Yale Journal on Regulation, 2013, Vol. 30.

Wyman, Katrina, "Second Generation Property Rights Issues", Natural Resources Journal, 2019, Vol. 59, Nº1.

ZÚÑIGA, Francisco, “Apostillas: ley y reglamento en la Jurisprudencia del tribunal constitucional (de la germanización al practicismo)", Revista Ius et Praxis, 2001, Vol. 7, n².

\section{b) Jurisprudencia:}

Pennsylvania Coal Company v. Mahon, 260 U.S. 393, 415 (1922).

Tribunal Constitucional, rol 115, sentencia de 3 de diciembre de 1990.

Tribunal Constitucional, rol No 207, sentencia de 10 de febrero de 1995.

Tribunal Constitucional, rol No 245-1996 y rol No 246-1996 (acumuladas), sentencia de 2 de diciembre de 1996

Tribunal Constitucional, rol No 260, sentencia de 1 de octubre de 1997.

Tribunal Constitucional, sentencia rol No 334-2001, de 21 de agosto de 2001

Tribunal Constitucional, rol No 505-2006, sentencia de 6 de marzo de 2007

Tribunal Constitucional, rol 2.386-12, sentencia de 23 de enero de 2012

Tribunal Constitucional, rol No 2299-2012, sentencia de 29 de enero de 2014

Tribunal Constitucional, Rol N ${ }^{0}$ 2684-2014-INA, sentencia de 10 de septiembre de 2015 (Caso Curtidos Bas).

Tribunal Constitucional, sentencia rol No 3112-2016, sentencia de 11 de agosto de 2016. 
Tribunal Constitucional, Rol 8614-20, sentencia de 12 de noviembre de 2020.

\section{c) Otros documentos:}

Biblioteca del Congreso Nacional (Editores), Historia de la Ley 19.713, establece como medida de administración el límite máximo de captura por armador a las Principales Pesquerías Industriales Nacionales y la regularización del Registro Pesquero Artesanal, BCN, Santiago, 2001, disponible en línea: https://www.bcn.cl/ historiadelaley/nc/historia-de-la-ley/6065/ (Fecha de visita: 12 de abril de 2021).

Biblioteca del Congreso Nacional (Editores), Historia de la Ley 20.017, modifica el Código de Aguas, BCN, Santiago, 2005, disponible en línea: https:// www.bcn.cl/historiadelaley/nc/historia-de-la-ley/5838/ (Fecha de visita: 12 de abril de 2021).

Concha, Germán, "Ley de Pesca y derechos de propiedad", opinión, Diario La Tercera, 12 de Julio de 2011.

CORREA, Jorge, "Límites constitucionales a eventuales modificaciones al régimen legal de pesca”, Informe en Derecho, ante Tribunal de Defensa de la Libre Competencia, Causa Rol NC 379-10, 2010.

Feliú, Olga, "Informe en Derecho en representación de Asipes, Asociación de Industriales Pesqueros de la VIII región", Informe en Derecho, ante Tribunal de Defensa de la Libre Competencia, Causa Rol NC 379-10, 2010.

MontT, Santiago, "Expropiaciones directas y derregulatorias y reforma regulatoria pesquera", Informe en Derecho, ante Tribunal de Defensa de la Libre Competencia, Causa Rol NC 379-10, 2010. 